\title{
Regulation of methylthioribose kinase by methionine in Klebsiella pneumoniae
}

\author{
Paula A. Tower,,${ }^{1,2}$ David B. Alexander, ${ }^{2}$ Linda L. Johnson ${ }^{1}$ and Michael K. Riscoe ${ }^{1,2,3 *}$ \\ ${ }^{1}$ Medical Research Service, 151-0, Department of Veterans Affairs Medical Center, 3710 SW US Veterans \\ Hospital Road, Portland, Oregon 97201, USA \\ Departments of ${ }^{2}$ Medicine and ${ }^{3}$ Biochemistry and Molecular Biology, Oregon Health Sciences University, \\ 3181 SW Sam Jackson Parkway, Portland, Oregon 97201, USA
}

(Received 6 July 1992; revised 30 November 1992; accepted 18 January 1993)

\begin{abstract}
5-Methylthioribose (MTR) kinase catalyses a key step in the recycling of methionine from 5 -methylthioadenosine, a co-product of polyamine biosynthesis, in Klebsiella pneumoniae. In defined medium lacking methionine, $K$. pneumoniae exhibits abundant MTR kinase activity. When the bacterium is transferred to a medium containing 10 mM-methionine, the specific activity of MTR kinase decreases in a fashion consistent with repression of new enzyme synthesis and dilution of existing enzyme by cell division. The specific activity of methionine synthase decreases to a similar degree under the same conditions. In Escherichia coli and Salmonella typhimurium, the gene for methionine synthase is co-ordinately controlled as part of the methionine regulon. Taken together, our results indicate that a methionine regulon may function in $K$. pneumoniae and that expression of MTR kinase may be under its control.
\end{abstract}

\section{Introduction}

In addition to its role as a structural component of proteins, methionine serves as a source of methyl groups for transmethylation reactions, as the 'initiator' amino acid during protein synthesis, and as the source of propylamine groups for synthesis of polyamines (Cooper, 1983). As a result, there is great demand for methionine in proliferating cells. Methionine is supplied both by de novo synthesis and by salvaging the amino acid. One important salvage pathway regenerates methionine from 5'-deoxy-5'-methylthioadenosine (MTA), thereby conserving the amino acid used during polyamine synthesis (Tabor et al., 1961; Williams-Ashman et al., 1982; Schlenk, 1983).

The MTA $\rightarrow$ methionine salvage pathway (Fig. 1) has been most extensively characterized in the Gramnegative bacterium Klebsiella pneumoniae. A specific nucleosidase cleaves MTA to 5-methylthioribose (MTR) and adenine (Duerre, 1962), at which point MTR may

*Author for correspondence (mail should be sent to the Medical Research Service address). Tel. (503) 721 7885; fax (503) 2735351.

Abbreviations: MTA, 5'-deoxy-5'-methylthioadenosine; MTR, 5-methylthioribose; KMB, 2-keto-4-methylthiobutyrate. be excreted (Schroeder et al., 1972, 1973) or recycled. Commitment to the methionine salvage pathway appears to begin with phosphorylation of the $\alpha$-oriented C-1 hydroxyl group of MTR by methylthioribose kinase, producing 5-methylthioribose 1-phosphate (MTR-1-P) (Ferro et al., 1978). Following isomerization and subsequent dehydration to a diketo intermediate (Trackman \& Abeles, 1983; Furfine \& Abeles, 1988), the molecule is oxidatively decarboxylated to 2-keto-4methylthiobutyrate (KMB) (Backlund et al., 1982), the immediate precursor to methionine.

While much has been accomplished regarding the enzymology of methionine recycling, studies on the regulation of this pathway have not been published. In this report, we present evidence indicating that the synthesis of MTR kinase is regulated by methionine in a manner analogous to control of the methionine regulon in Escherichia coli and Salmonella typhimurium (Saint Girons et al., 1988).

\section{Methods}

Bacterial culture conditions. A clinical isolate of $K$. pneumoniae was grown in a chemically defined methionine-free medium (Gianotti et al., $1990)$ at $37^{\circ} \mathrm{C}$ with vigorous shaking. At mid-exponential phase, the cells were washed twice, diluted 20 -fold in the defined medium, and $0.4 \mathrm{ml}$ of the dilute suspension was inoculated into $25 \mathrm{ml}$ of defined 


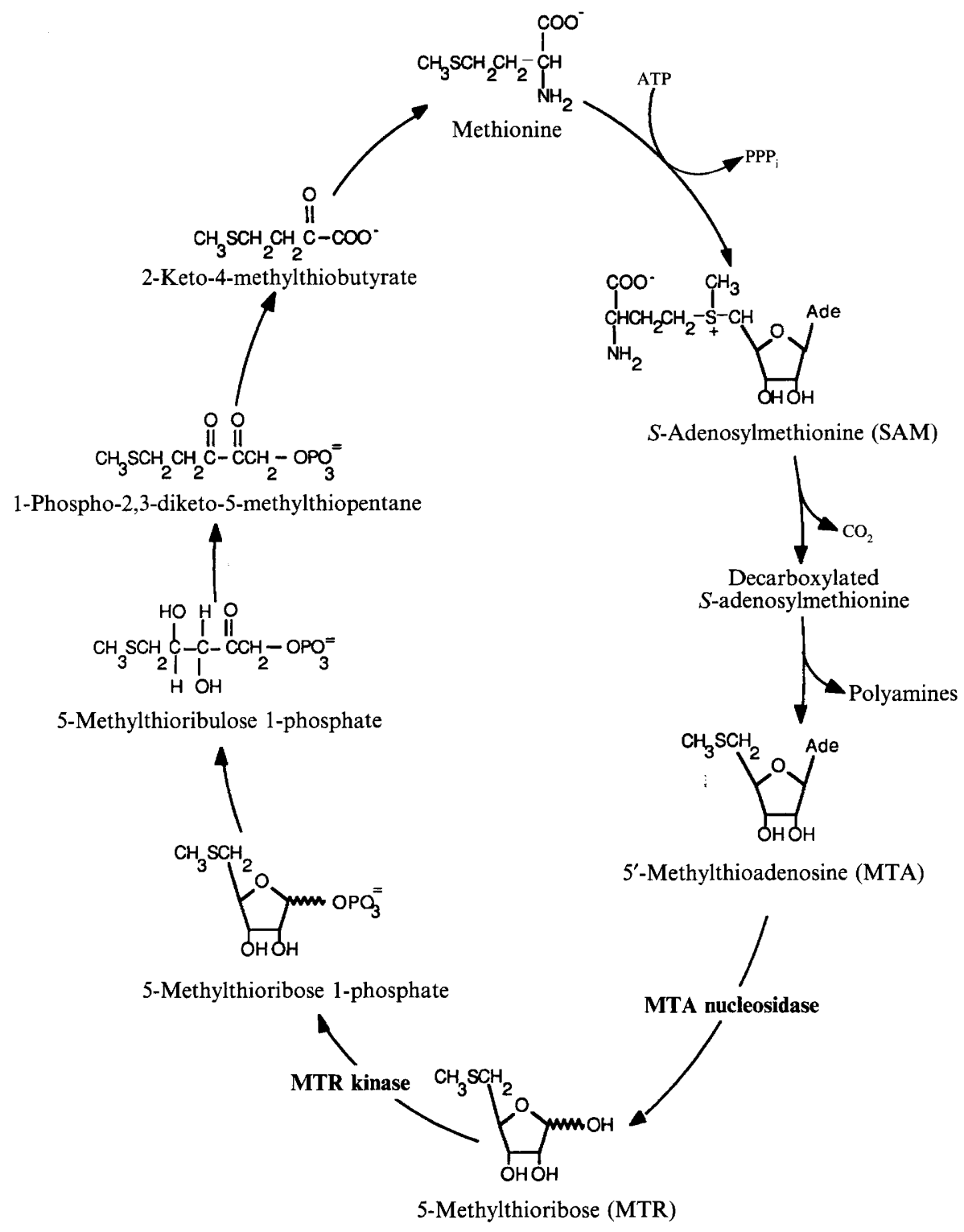

Fig. 1. Salvage of methionine during polyamine biosynthesis in K. pneumoniae.

medium containing $1 \mu \mathrm{M}$ - to $10 \mathrm{~mm}$-methionine (initial $\mathrm{OD}_{470}$ reading $\sim 0.02$ ). The cultures were incubated at $37^{\circ} \mathrm{C}$ with shaking. Cells were harvested at regular intervals by centrifugation, and washed twice with defined medium.

Enzyme assays. Cell pellets were resuspended in 5 vols $(\mathrm{ml}$ per g wet wt) of $0.05 \mathrm{M}$-Tris $/ \mathrm{HCl}$ buffer (pH 8.0) containing $1 \mathrm{~mm}$-dithiothreitol and passed through a French pressure cell twice at $16000 \mathrm{lbf} \mathrm{in}^{-2}$ (about $110 \mathrm{MPa}$ ). Cellular debris was removed by centrifugation, and the supernatants were dialysed against three changes of 1 litre Tris/DTT buffer (as above) at $4{ }^{\circ} \mathrm{C}$. The dialysed extracts were used without further modification for all subsequent enzyme analyses. Protein concentrations were determined by the method of Bradford (1976), using bovine serum albumin as the standard.

MTR kinase activity was assayed as described by Gianotti et al. (1990). The amount of extract added per assay was adjusted to achieve $<10 \%$ substrate conversion during a 30 min incubation. Vitamin- $B_{12}$ dependent methionine synthase assays were done as described by Fujii
\& Huennekens (1974), using DTT as a chemical reducing agent. MTA nucleosidase and ornithine decarboxylase were assayed as described by Duerre (1962) and Bitonti et al. (1982), respectively.

The transaminase activity involved in conversion of 2-keto-4methylthiobutyrate to methionine was assayed in the presence of glutamine under conditions described for rat liver glutamine transaminase (Cooper \& Meister, 1972) with slight modification. The assay system contained (in a final volume of $0.1 \mathrm{ml}$ ) $20 \mathrm{mM}$-glutamine, $50 \mathrm{~mm}$-Tris $/ \mathrm{HCl}$ buffer (pH 8.5), 2 mM-2-keto-4-[Me- $\left.{ }^{3} \mathrm{H}\right]$ methylthiobutyrate $\left(3.1 \times 10^{7}\right.$ c.p.m. $\left.\mu \mathrm{mol}^{-1}\right)$, pyridoxal $5^{\prime}$-phosphate $(80 \mu \mathrm{M})$ and dialysed extract. Activity was shown to require the presence of pyridoxal 5'-phosphate. After incubation for $10-120 \mathrm{~min}$ at $37^{\circ} \mathrm{C}$, the reaction was stopped and formation of radiolabelled methionine was determined. Tris $/ \mathrm{HCl}$ buffer $(50 \mu \mathrm{l}, \mathrm{pH} 7 \cdot 2)$ containing $3 \mathrm{~mm}$-DTT was added and the assay mixture was applied to a Bio-Rad AG50-X8 resin $\left(\mathrm{H}^{+}\right.$form, 100-200 mesh, $\left.0.5 \times 1 \mathrm{~cm}\right)$. The column was washed three times with $5 \mathrm{ml}$ of water. Methionine was eluted by application of two $3 \mathrm{ml}$ aliquots of $4 \mathrm{M}-\mathrm{NH}_{4} \mathrm{OH}$ which were combined and taken to 
dryness in vacuo. The dried residue was resuspended in $1 \mathrm{ml}$ of water, mixed with ReadySafe cocktail (Beckman), and counted in a scintillation counter.

\section{Results}

Effect of methionine on the specific activities of enzymes related to methionine salvage in $K$. pneumoniae

The activity of highly purified MTR kinase is not inhibited in vitro by methionine ( $1 \mathrm{mM})$, the end-product of the salvage pathway, or by its metabolite $S$ adenosylmethionine $(0.8 \mathrm{mM})$ (M. K. Riscoe \& P. A. Tower, unpublished observations). To test whether MTR kinase activity is influenced by exogenous methionine in vivo, $K$. pneumoniae was cultured in the presence of various concentrations of methionine for three generation times, and the specific activity of the enzyme was measured. The results are presented in Fig. 2. K. pneumoniae grown in defined medium in the absence of methionine exhibited abundant MTR kinase activity [494 $\mathrm{pmol} \mathrm{min}^{-1}$ (mg protein) ${ }^{-1}$. Greater activity was observed in extracts of bacteria cultured in $1 \mu \mathrm{M}-$ methionine [ $\left.738 \mathrm{pmol} \mathrm{min}^{-1}(\mathrm{mg} \text { protein })^{-1}\right]$. Growth in higher concentrations of methionine $(>1 \mu \mathrm{M})$ decreased the specific activity of MTR kinase. At methionine concentrations of $0.05 \mathrm{~mm}$ or greater, the specific activity of MTR kinase decreased by $90-95 \%$ as compared to the methionine-free control.

The observation that the level of MTR kinase activity in $K$. pneumoniae was subject to regulation by methionine suggested a parallel to the methionine regulon genes of E. coli and S. typhimurium. As a result, the extracts used to assess MTR kinase activity were also assayed for the activity of methionine synthase, an enzyme whose expression is controlled as part of the methionine regulon in E. coli and S. typhimurium. As shown in Fig. 2, the specific activity of methionine synthase decreased as the methionine concentration increased, with a significant reduction observed at $0.05 \mathrm{~mm}$-methionine $[\sim 47.3 \%$ of the control value of $\left.0.239 \mathrm{nmol} \mathrm{min}^{-1}(\mathrm{mg} \text { protein })^{-1}\right]$. A further fall occurred with $10 \mathrm{~mm}$-methionine present in the culture medium. After three generations, the specific activity fell to $19 \cdot 2 \%$ of control values. These results are similar to the findings of Rowbury \& Woods, who described the repression of synthesis of methionine synthase by exogenous methionine in $E$. coli (Rowbury \& Woods, 1961).

We also examined the possibility that other enzymes related to the MTA $\rightarrow$ methionine salvage pathway are controlled by exogenous methionine. Cell extracts derived from bacteria grown in various concentrations of methionine were tested. The specific activity of MTA nucleosidase, the degradative enzyme responsible for synthesis of MTR from MTA, was unaffected by

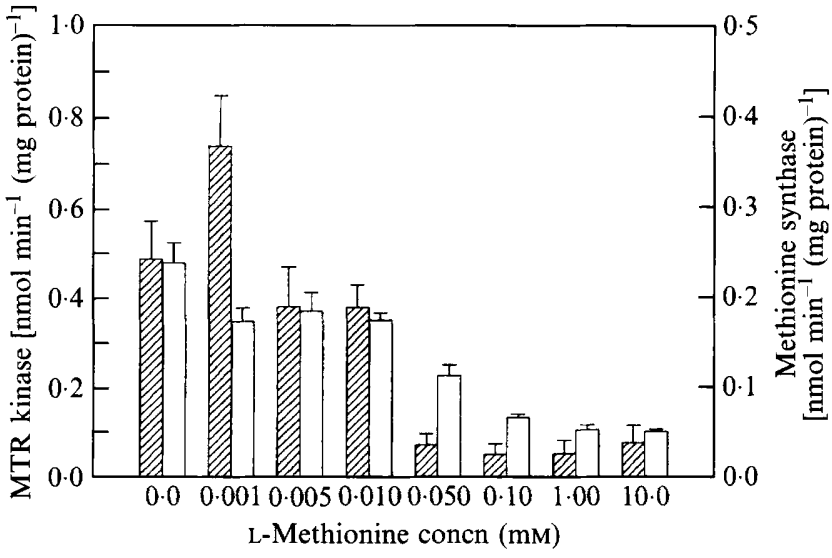

Fig. 2. Effect of exogenous methionine on the specific activity of MTR kinase ( $\square$ ) and methionine synthase $(\square)$ in $K$. pneumoniae. Points reflect the mean value and standard error from at least three separate experiments, each performed in duplicate.

addition of exogenous methionine to the culture medium (Fig. 3). Similarly, the specific activity of ornithine decarboxylase, an enzyme involved in synthesis of polyamines, was not influenced by methionine concentrations over the range tested (Fig. 3). The activity of a transaminase is responsible for conversion of $\mathrm{KMB}$ to methionine, the final step in the MTA $\rightarrow$ methionine salvage pathway. As shown in Fig. 3, this transaminase activity was abundant in $K$. pneumoniae extracts and the specific activity of the enzyme was not altered relative to the concentration of methionine added to the culture medium. Thus, while the specific activity of MTR kinase decreased in bacteria exposed to increasing concentrations of methionine, enzymes not directly related to methionine recycling appeared to be unaffected.

\section{Effect of exogenous methionine on the synthesis of $M T R$ kinase in K. pneumoniae}

To examine more closely the process of repression of MTR kinase activity by methionine, we cultured $K$. pneumoniae in defined medium in the absence of exogenous methionine, then transferred cells to medium containing $10 \mathrm{~mm}$-methionine. Cell-free extracts were prepared from samples taken at $\mathbf{4 5}$ min intervals (equal to one generation time under these culture conditions), and assayed for MTR kinase activity (Fig. 4). The specific activity of MTR kinase decreased roughly $50 \%$ with each doubling time through three generations. For example, MTR kinase specific activity at the start of the experiment was $191.3 \pm 24.3 \mathrm{pmol} \mathrm{min}^{-1}$ (mg protein) ${ }^{-1}$. Within $45 \mathrm{~min}$ in the presence of methionine, the level of MTR kinase activity decreased $49 \cdot 1 \%$ of initial control values. A control culture in which the organism was maintained in medium without methionine showed no 


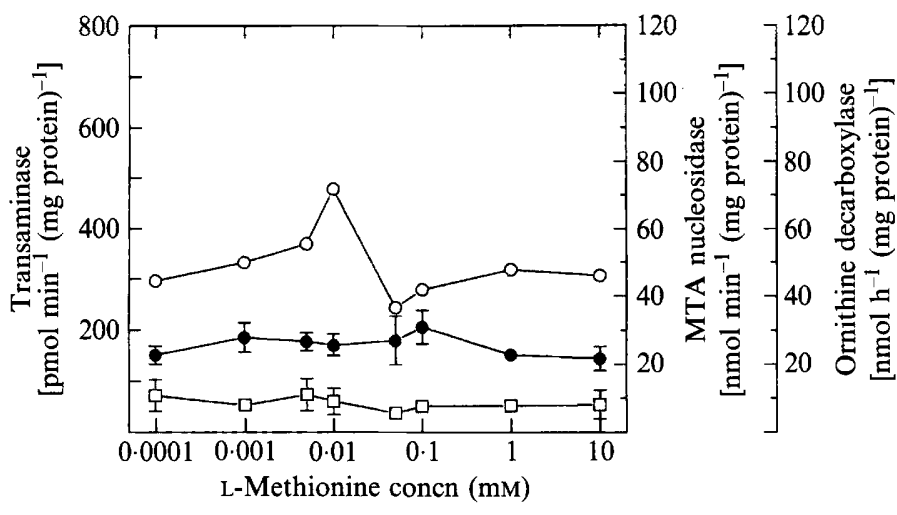

Fig. 3

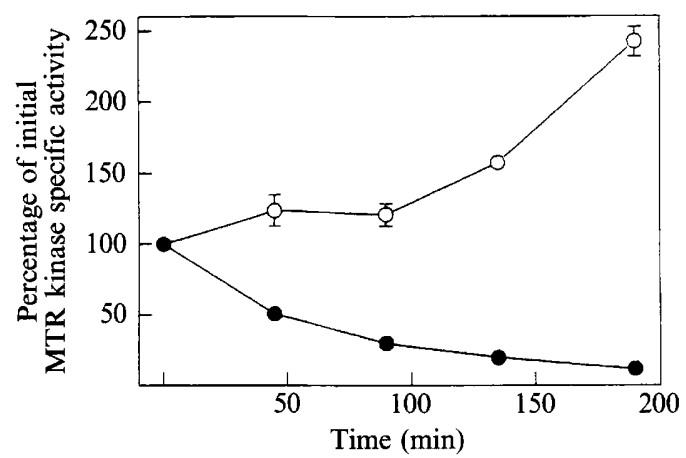

Fig. 4

Fig. 3. Effect of exogenous methionine on the specific activities of MTA nucleosidase ( $)$, ornithine decarboxylase ( $\square$ ) and the transaminase $(O)$ responsible for conversion of KMB to methionine in $K$. pneumoniae. Points reflect the mean value and standard error of at least three separate determinations carried out in duplicate.

Fig. 4. Effect of exogenous methionine on the specific activity of MTR kinase in K. pneumoniae with time. $\bigcirc$, Without methionine; - with $10 \mathrm{~mm}$-methionine. Points reflect the mean value and standard error of three separate determinations carried out in duplicate

significant change in specific activity until $135 \mathrm{~min}$ of incubation, when an increase (for reasons as yet obscure) was exhibited.

\section{Discussion}

In the enteric bacteria $E$. coli and $S$. typhimurium, addition of methionine to the growth medium represses the synthesis of methionine biosynthetic enzymes (Saint Girons et al., 1988). In this report, we describe another enzyme, MTR kinase, which appears to be under the control of methionine. MTR kinase catalyses the first step in the conversion of MTR to methionine in $K$. pneumoniae. Activity of this enzyme is not subject to feedback inhibition by end-products of MTR metabolism. When cells grown in the absence of methionine are transferred to a medium containing 10 mM-methionine, however, the specific activity of MTR kinase falls $\sim 50 \%$ with each generation time. These results are consistent with other enzymes regulated by methionine (Rowbury \& Woods, 1961; Rowbury et al., 1968), suggesting that repression of MTR kinase synthesis may occur, resulting in a simple dilution of enzyme with cell division. However, in the absence of antibodies specific for MTR kinase, this conclusion results from experiments of an indirect nature and must be taken as an indication rather than a direct demonstration of the inhibition of synthesis of MTR kinase.

It is not known whether the gene encoding MTR kinase and the genes encoding the other salvage pathway enzymes are controlled as an operon or as part of a methionine regulon. Awareness of the co-ordinated control of the methionine regulon has come from studies of $E$. coli and $S$. typhimurium, bacteria that do not recycle MTR to methionine (Ferro et al., 1978). It has yet to be shown whether a methionine regulon functions in $K$. pneumoniae. Our finding that methionine synthase activity in $K$. pneumoniae is regulated by the level of methionine in the culture medium suggests the presence of a methionine repressor or an analogous controlling element.

Exogenous methionine did not affect the activities of related enzymes, including ornithine decarboxylase, MTA nucleosidase, and the transaminase which acts upon KMB. Ornithine decarboxylase catalyses a primary step in the synthesis of polyamines, which are important for proliferating cells, and MTA nucleosidase degrades MTA, a potentially toxic co-product of polyamine synthesis. Therefore, the absence of any effect by methionine on these enzymes was not surprising. Neither was the lack of inhibition of the transaminase responsible for catalysing the KMB to methionine conversion, which is likely to function in the amination of many $\alpha$-keto acids to the corresponding amino acids used for protein synthesis (Cooper \& Meister, 1972, 1974). Taken together, the data suggest that $K$. pneumoniae responds to an environment rich in methionine by efficiently repressing its methionine recycling capacity while continuing to synthesize polyamines and degrade MTA. Based on this example of cellular economy, one might presume that the mechanism of methionine-induced enzyme repression regulates the synthesis of other enzymes specific to the MTA $\rightarrow$ methionine recycling pathway, e.g. 1-phospho-2,3-diketo-5-S-methyl-5thiopentane dioxygenase (Furfine \& Abeles, 1988).

The results of this study also provide clues as to the mechanism by which antagonists of methionine biosynthesis potentiate the effect of 5-trifluoromethyl- 
thioribose (TFMTR), an analogue of MTR which inhibits the growth of K. pneumoniae (Tower et al., 1991). Inhibitors of methionine synthesis may lower intracellular levels of methionine, resulting in increased synthesis of MTR kinase (and perhaps other enzymes in the salvage pathway), thereby leading to increased conversion of TFMTR to toxic products.

In summary, it appears that MTR kinase is subject to repression by methionine in a fashion similar to other enzymes involved in the biosynthesis of methionine. Further studies on the regulation of MTR kinase at the molecular level will be important for elucidating the control mechanisms and the possible involvement of a methionine regulon.

This investigation received financial support from the Veterans Affairs Merit Review Program and the Medical Research Foundation of Oregon. Additional support was from Epitope, Inc. of Beaverton, Oregon.

\section{References}

Backlund, P. J., Chang, C. P. \& Smith, R. A. (1982). Identification of 2-keto-4-methylthiobutyrate as an intermediate compound in methionine synthesis from 5'-methylthioadenosine. Journal of Biological Chemistry 257, 4196-4202.

Bitonti, A. J., McCanN, P. P. \& Sjoerdsma, A. (1982). Restriction of bacterial growth by inhibition of polyamine biosynthesis by using monofluoromethylornithine, diffuoromethylarginine and dicyclohexylammonium sulphate. Biochemical Journal 208, 435-441.

BRADFORD, M. M. (1976). A rapid and sensitive method for the quantitation of microgram quantities of protein utilizing the principle of protein-dye binding. Analytical Biochemistry 72, 248-254.

COOPER, A. J. (1983). Biochemistry of sulfur-containing amino acids. Annual Review of Biochemistry 52, 187-222.

COOPER, A. J. L. \& MEISTER, A. (1972). Isolation and properties of highly purified glutamine transaminase. Biochemistry 11, 661-671.

COOPER, A. J. \& MeISTER, A. (1974). Isolation and properties of a new glutamine transaminase from rat kidney. Journal of Biological Chemistry 249, 2554-2561.

DUERRE, J. A. (1962). A hydrolytic nucleosidase acting on Sadenosylhomocysteine and on 5'-methylthioadenosine. Journal of Biological Chemistry 237, 3737-3741.
Ferro, A. J., BarretT, A. \& Shapiro, S. K. (1978). 5-Methylthioribose kinase. A new enzyme involved in the formation of methionine from 5-methylthioribose. Journal of Biological Chemistry 253, 6021-6025.

FujII, K. \& HuENNekens, F. (1974). Activation of methionine synthetase by a reduced triphosphopyridine nucleotide-dependent flavoprotein system. Journal of Biological Chemistry 249, 6745-6753.

FURFINE, E. S. \& ABELES, R. H. (1988). Intermediates in the conversion of 5'-S-methylthioadenosine to methionine in Klebsiella pneumoniae. Journal of Biological Chemistry 263, 9598-9606.

Gianotti, A. J., Tower, P. A., Sheley, J. H., Conte, P. A., Spiro, C., Ferro, A. J., Fitchen, J. H. \& Riscoe, M. K. (1990). Selective killing of Klebsiella pneumoniae by 5-trifluoromethylthioribose. Chemotherapeutic exploitation of the enzyme 5-methylthioribose kinase. Journal of Biological Chemistry 265, 831-837.

Rowbury, R. J. \& Woods, D. D. (1961). Further studies on the repression of methionine synthesis in Escherichia coli. Journal of General Microbiology 24, 129-144.

Rowbury, R. J., LaWrence, D. A. \& Smirh, D. A. (1968). Regulation of the methionine-specific aspartokinase and homoserine dehydrogenase of Salmonella typhimurium. Journal of General Microbiology 54, 337-342.

Saint Girons, I., Parsot, C., Zakin, M. M., Barzu, O. \& Cohen, G. N. (1988). Methionine biosynthesis in Enterobacteriaceae: biochemical, regulatory, and evolutionary aspects. CRC Critical Reviews in Biochemistry 23, 1-41.

SCHLENK, F. (1983). Methylthioadenosine. Advances in Enzymology 54, 195-265.

Schroeder, H. R., Barnes, C. J., Bohinski, R. C., Mumma, R. O. \& MALLETTE, M. F. (1972). Isolation and identification of 5-methylthioribose from Escherichia coli B. Biochimica et Biophysica Acta 273, 254-264.

SCHroeder, H. R., Barnes, C. J., Bohinski, R. C. \& Mallette, M. F. (1973). Biological production of 5-methylthioribose. Canadian Journal of Microbiology 19, 1347-1354.

TABOR, H., TABOR, C. W. \& Rosenthal, S. M. (1961). The biochemistry of the polyamines: spermidine and spermine. Annual Reviews of Biochemistry 30, 579-604.

Tower, P. A., Johnson, L. L., Ferro, A. J., Fitchen, J. H. \& Riscoe, M. K. (1991). Synergistic activity of 5-trifluoromethylthioribose and inhibitors of methionine synthesis against Klebsiella pneumoniae. Antimicrobial Agents and Chemotherapy 35, 1557-1561.

Trackman, P. C. \& ABeles, R. H. (1983). Methionine synthesis from 5'-S-Methylthioadenosine. Resolution of enzyme activities and identification of 1-phospho-5-S-methylthioribulose. Journal of Biological Chemistry 258, 6717-6720.

Williams-Ashman, H. G., Seidenfeld, J. \& Galletti, P. (1982). Trends in the biochemical pharmacology of 5'-deoxy-5'-methylthioadenosine. Biochemical Pharmacology 31, 277-288. 